\title{
PRODUÇÃO TEXTUAL NA FORMAÇÃO PROFISSIONAL DO ALUNO DO PROEJA POR MEIO DE PROJETOS DIDÁTICOS
}

\section{TEXTUAL PRODUCTION IN THE PROFISSIONAL FORMATION OF PROEJA STUDENTS BY MEANS OF DIDACTIC PROJECTS}

\author{
Rosana de Oliveira Sá ${ }^{1}$ \\ Linduarte Pereira Rodrigues ${ }^{2}$
}

\begin{abstract}
RESUMO: A Educação de Jovens e Adultos (EJA) é uma modalidade com particularidades que a distingue da Educação Básica Regular. A concepção de mundo de uma pessoa que regressa aos estudos na idade adulta é bem peculiar, uma vez que já tem crenças e valores consolidados. Além disso, esses jovens e adultos vivem no mundo do trabalho, têm responsabilidades sociais e familiares, formaram seus valores éticos e morais a partir da realidade sócio-econômica-cultural em que estão inseridos. A partir disso, este estudo objetivou desenvolver uma proposta metodológica para ressignificação do ensino de produção textual nas aulas de Língua Portuguesa, especificamente no contexto do PROEJA. Para tanto, baseou-se nos estudos do letramento (SUASSUNA; MELO; COELHO, 2006; ROJO, 2009); na multimodalidade (DIONÍSIO; VASCONCELOS, 2013; RIBEIRO, 2016); e nos documentos oficiais que regulamentam o ensino de Língua Portuguesa no Ensino Médio. Metodologicamente, trata-se de uma pesquisa qualitativa, do tipo pesquisa-ação. Os dados foram coletados por meio de observação participante e das produções textuais dos colaboradores da pesquisa. Os resultados revelam a importância de projetos de letramento didático-temáticos que valorizem práticas pedagógicas voltadas para a construção da cidadania e para as reais necessidades sociais e profissionais dos discentes da EJA, aproveitando o conhecimento de mundo que eles adquiriram naturalmente como diferencial facilitador do processo de letramento escolar.
\end{abstract}

PALAVRAS-CHAVE: PROEJA. Produção textual. Projetos. Letramento. Multimodalidade.

ABSTRACT: Youth and Adult Education (YAE) is a modality with particularities which distinguishes it from Regular Basic Education. The worldview of an individual resuming to studies at adulthood is quite peculiar, as their beliefs and values have already been consolidated. Moreover, these young people and adults live in the world of work, have social and family responsibilities, and have formed their ethical and moral values based on the socioeconomic and cultural reality in which they are inserted. From this point of view, this study aimed at developing a methodological proposal to resignify the teaching of textual production in Portuguese language classes, specifically in the context of PROEJA. It was based on literacy studies (SUASSUNA; MELO; COELHO, 2006; ROJO, 2009); on multimodality (DIONÍSIO; VASCONCELOS, 2013; RIBEIRO, 2016); and on the official documents that regulate the teaching of Portuguese Language in High School. Methodologically, it is a qualitative research, of the action research type. Data were collected through participant observation and from the research collaborators' textual productions. The results reveal the importance of didactic-themed literacy projects that value pedagogical practices aimed at the construction of citizenship as well the real social and professional needs of the students from EJA, taking advantage of the knowledge of the world that they have naturally acquired as a differential facilitator of the school literacy process.

KEYWORDS: PROEJA. Textual production. Projects. Literacy. Multimodality.

\section{Introdução}

No campo das políticas educacionais, a EJA Profissionalizante, estabelecida pelo Decreto $\mathrm{n}^{\mathrm{o}}$. 5.478, de 24 de junho de 2005, foi uma decisão governamental proposta como alternativa para a formação de trabalhadores no Brasil. Tal medida promoveu a integração das

\footnotetext{
${ }^{1}$ Mestre em Formação de Professores pela Universidade Estadual da Paraíba (PPGFP-UEPB). Professora Efetiva do Instituto Federal da Paraíba (IFPB/JP). Membro do grupo de pesquisa Teorias do sentido: discursos e significações (TEOSSENO-CNPq/UEPB) E-mail: rosana.sa@ifpb.edu.br

2 Doutor em Linguística pela Universidade Federal da Paraíba (PROLING-UFPB). Professor do Departamento de Letras e Artes da Universidade Estadual da Paraíba e membro do corpo docente do Programa de Pós-Graduação em Formação de Professores (PPGFP-UEPB) - Campus I. Líder do grupo de pesquisa Teorias do sentido: discursos e significações (TEOSSENO-CNPq/UEPB).E-mail: linduartepr@gmail.com
} 
modalidades de Educação de Jovens e Adultos (EJA) e Educação Profissional, visando, além da certificação técnica, à elevação da escolaridade. Em seguida, por meio do Decreto $\mathrm{n}^{\circ} .5 .840$ de 13 de julho de 2006, foi ampliado em termos de abrangência e aprofundado em seus princípios pedagógicos, passando a se chamar oficialmente Programa Nacional de Integração da Educação Profissional com a Educação Básica na Modalidade de Educação de Jovens e Adultos (doravante PROEJA). Com isso, passou a agregar três segmentos da educação: Educação Básica; Educação Profissional; e Educação de Jovens e Adultos.

Esta modalidade de ensino, inicialmente ofertada pela Rede Federal de Educação Profissional e Tecnológica, apresenta particularidades que a distingue da Educação Básica Regular, uma vez que a concepção de mundo de uma pessoa que regressa aos estudos na idade adulta é bem peculiar, visto que tem crenças e valores consolidados. Na sua maioria, é composta por jovens e adultos que vivem no mundo do trabalho, têm responsabilidades sociais e familiares, formaram seus valores éticos e morais a partir da realidade sócio-econômica-cultural em que estão inseridos.

Assim sendo, a proposta pedagógica praticada na sala de aula, a qual prioriza a leitura e produção de textos de várias esferas de atividades (MARCUSCHI, 2008), nas mais diversas linguagens e semioses (ROJO, 2009; RIBEIRO, 2016), deveria ser o objetivo primeiro do processo de ensino e aprendizagem de uma língua para esse alunado específico. Contraditoriamente, nos diversos contextos de ensino de língua materna vivenciados, enquanto docentes, o modo descontextualizado de ensinar ainda é a realidade vigente.

Diante do exposto, o objetivo geral do estudo é desenvolver uma proposta metodológica para as aulas de Língua Portuguesa do PROEJA que possibilite a produção de textos condizentes com as necessidades profissionais e cotidianas dos alunos dessa modalidade de ensino, valendo-se das teorias do letramento, da multimodalidade e de projetos didáticos /temáticos ${ }^{3}$.

\section{Referencial teórico-documental}

No que tange à Educação de Jovens e Adultos, em especial ao PROEJA, o Documento Base (BRASIL, 2007a) atestou que essa modalidade de ensino se caracteriza por atender a um grupo composto, basicamente, por trabalhadores com experiências escolares marcadas por períodos de afastamento e por reprovações. Portanto, os conhecimentos de leitura e de produção textual dos sujeitos do PROEJA não se constroem, exclusivamente, pela escolarização, mas também por saberes que vêm de outros contextos, das interações sociais e das diversificadas experiências pessoais e profissionais. Por isso, é viável a inserção de práticas de letramento no processo de ensino e aprendizagem desses educandos, visto que promovem a vivência da cidadania e podem minimizar os efeitos das desigualdades sociais.

Acerca das concepções de linguagem e das práticas de ensino com letramentos múltiplos, as Orientações Curriculares para o Ensino Médio (BRASIL, 2006, p.28) enfatizam:

A lógica de uma proposta de ensino e de aprendizagem que busque promover letramentos múltiplos pressupõe conceber a leitura e a escrita como ferramentas de empoderamento e inclusão social. Some-se a isso que as práticas de linguagem a serem tomadas no espaço da escola não se restringem à palavra escrita nem se filiam apenas aos padrões socioculturais hegemônicos.

\footnotetext{
${ }^{3}$ Utilizaremos estes termos propostos por Suassuna, Melo e Coelho (2006, p.232) sempre que nos referirmos ao projeto que desenvolvemos para a parte aplicada desta pesquisa.
} 
Entendemos que o professor tem a opção de ressignificar as práticas de linguagem dentro do contexto das comunidades em que a escola está incluída, através de textos que melhor reproduzam a realidade dos educandos. Tal atitude possibilitará aos alunos uma conscientização não apenas da própria condição, mas também da comunidade na qual estão inseridos, auxiliando-os, assim, a atuarem como protagonistas (BRASIL, 2000; 2002; 2013) na ação coletiva e na realização de seus sonhos profissionais e pessoais.

Ao refletirmos acerca das metodologias de ensino de Língua Portuguesa a partir da Linguística Aplicada, destacamos os projetos como instrumentos facilitadores da aprendizagem. Visto que tal prática, nas aulas de língua, ativa a dimensão sociocomunicativa da linguagem, como também se articula às noções de letramentos, gêneros e interdisciplinaridade, as quais vão direcionar uma metodologia de ensino voltada para práticas linguageiras (BRONCKART, 2006) que se desenvolvem em contextos situados, dinâmicos, em meio a trocas interativas nas quais os interlocutores, o tema, o propósito e a situação comunicativa desempenham um papel fundamental.

Ademais, letramento e gêneros textuais são conceitos relevantes para o entendimento do uso da linguagem como prática social, assim como sua relação com o desenvolvimento de projetos e com a noção de interdisciplinaridade. Rojo $(2009$, p.11) afirma que um dos papéis da escola no mundo atual é possibilitar que os discentes "participem das várias práticas sociais que se utilizam da leitura e da escrita (letramentos) na vida da cidade, de maneira ética, crítica e democrática". Segundo a autora, para que isso aconteça, é necessário que a educação linguística trabalhe: i) os multiletramentos, valorizando não apenas os letramentos valorizados universalmente, mas também os letramentos das culturas locais; ii) os letramentos multissemióticos, trabalhando a leitura e produção textual em diversas linguagens (verbal oral e escrita, musical, imagética etc.); iii) letramentos críticos, desvelando as reais intenções, finalidades e ideologias presentes nos textos (ROJO, 2009, p. 119-120). Letramentos que valorizamos nas fases de elaboração e de execução do módulo didático que desenvolvemos para este estudo, uma vez que são geralmente requeridos nas práticas sociais contemporâneas.

Cabe ressaltar que o elemento desencadeador de um projeto pode ser uma questão problema, que emerge do contexto em que os sujeitos que dele participam estão situados; do projeto político-pedagógico da escola e da disciplina (SUASSUNA; MELO; COELHO, 2006); ou pode ser guiado por temas geradores que sirvam como eixo orientador e estímulo para os sujeitos que dele participam. No entanto, é importante que a escolha desses temas parta de um consenso coletivo que propicie o entrosamento e engajamento de todo o grupo participante.

No tocante às vantagens de lecionar via projetos didáticos, destacamos o rompimento com o ensino pouco interativo e caracterizado pela prescrição, como também a possibilidade de tratar os conteúdos de modo articulado e contextualizado. Oliveira, Tinoco e Santos (2014, p.58) alertam que tal prática requer o rompimento com: i) a fragmentação dos conteúdos determinados nas grades curriculares; ii) o protagonismo do professor nas aulas de linguagem; o ensino centrado em conteúdos gramaticais; iii) as avaliações voltadas exclusivamente para o processo de assimilação da informação gramatical recebida na sala de aula.

Já os instrumentos de políticas educacionais e linguísticas - como os PCNEM (BRASIL, 2000), PCN+ (BRASIL, 2002) - ressaltam que a atividade de escrever pode se tornar mais difícil se os textos escolhidos para o trabalho em sala de aula não forem genuínos, como também se os interlocutores com os quais esses textos dialogam forem mera ficção. E nessa perspectiva de atender às expectativas dos estudantes e às demandas da sociedade contemporânea, a Base Nacional Comum Curricular (BRASIL, 2018, p.463) enfatiza a necessidade de organizar uma escola de Ensino Médio que "garanta aos estudantes ser protagonistas de seu próprio processo de escolarização, reconhecendo-os como interlocutores legítimos sobre currículo, ensino e aprendizagem". Sendo assim, torna-se imperativo excluir práticas de ensino descontextualizadas ainda recorrentes em alguns ambientes educacionais. 
Ao considerarmos que o aluno do Ensino Médio Profissionalizante precisa envolver-se em práticas de letramento escolar que oportunizem o desenvolvimento de suas habilidades multiletradas em diferentes esferas sociais, entendemos a necessidade de planejamentos de ensino que façam uso de projetos didático-temáticos. Sobre isso, Suassuna, Melo e Coelho (2006, p.232-233) explicam:

$\mathrm{O}$ projeto didático/temático permite recuperar o movimento intrínseco à prática da linguagem: ler o que o outro disse; comparar com um outro dizer de um outro sujeito; verificar as diferentes formas de dizer; ter o próprio texto lido; procurar dizer de um certo modo; buscar informações sobre como dizer; avaliar os diferentes efeitos de sentido de dizer...são práticas de professores e alunos que, juntos, atuam como produtores de significados.

Ou seja, os projetos podem funcionar como uma maneira de organizar os conhecimentos escolares, porém de forma flexível e adaptável, de acordo com as especificidades dos discentes e /ou da turma como um todo.

Ademais, na contemporaneidade, com a disseminação das tecnologias, os textos vêm constantemente adquirindo novas configurações, que transcendem as palavras, as frases e, acima de tudo, a modalidade escrita da linguagem. As novas Tecnologias da Informação e Comunicação não apenas promoveram o surgimento de uma diversidade de gêneros textuais, mas também revelaram a urgência da escola lidar com a linguagem multimodal em todas as disciplinas do currículo escolar, uma vez que nossas interações cotidianas acontecem via múltiplas linguagens e semioses (ROJO, 2009; RIBEIRO, 2016). Consequentemente, os gêneros textuais - mediadores de nossas interações sociais - materializam-se em textos multimodais.

Diante disso, é relevante chamar a atenção dos discentes para o fato de que a escolha dos elementos verbais e não verbais que configurarão seus textos não é e/ou não deve ser feita de forma aleatória. Ao contrário, recursos multimodais como tamanho e tipo de fonte, cores, paragrafação, leiaute de página e imagens são instruções para a elaboração de significados em situações de interação.

Nesse viés, Dionísio e Vasconcelos (2013, p.22) - pautadas na Teoria Cognitiva da Aprendizagem Multimodal (TCAM) ${ }^{4}$ - abordam "o fenômeno da multimodalidade como traço constitutivo dos gêneros textuais e como recurso metodológico" em contextos de aprendizagem de leitura e de produção textual. Perspectivas que foram consideradas na fase aplicada da pesquisa, uma vez que demonstramos aos discentes como utilizar variadas formas de linguagens na construção de sentidos dos textos que lemos e produzimos, assim como incentivamos o uso de recursos multimodais nas atividades de produção textual desenvolvidas no decorrer de nosso projeto didático.

Ao abordar as competências específicas da área de Linguagens e suas Tecnologias para o Ensino Médio, a BNCC (BRASIL, 2018, p.493) orienta:

Utilizar diferentes linguagens (artísticas, corporais e verbais) para exercer, com autonomia e colaboração, protagonismo e autoria na vida pessoal e coletiva, de forma crítica, criativa, ética e solidária, defendendo pontos de vista que respeitem o outro e promovam os Direitos Humanos, a consciência socioambiental e o consumo responsável, em âmbito local, regional e global.

\footnotetext{
${ }^{4}$ Dionísio e Vasconcelos (2013, p. 34) explicam que a teoria TCAM, desenvolvida por Mayer (2001; 2009), parte da premissa de que estudantes aprendem melhor a partir de uma explanação apresentada em palavras e em imagens do que daquela apresentada apenas em palavras. Para aprofundar tal discussão, indicamos a leitura do capítulo 1 de Multimedia Learning (MAYER, 2009).
} 
Esse foco na construção da autonomia dos discentes nas práticas de compreensão e de produção em diferentes linguagens nos alerta para a urgência de mudanças no ensino de língua materna, com vistas a um currículo que considere as mais variadas situações sociais que um indivíduo possa vivenciar, e que não valorize o ensino da norma culta apenas.

Também, os estudos elencados nesta seção revelam que não há mais espaço para uma "escrita vazia, de palavras soltas, de frases soltas, de frases inventadas" (ANTUNES, 2003, p.115), uma vez que esse tipo de prática não condiz com o mundo real dos discentes. Fato que nos motivou a repensar nossas práticas pedagógicas, a refletir sobre o material didático utilizado PROEJA IFPB/JP - locus da pesquisa - e, consequentemente, a elaborar e aplicar uma proposta para o ensino de produção textual nas aulas de Língua Portuguesa especificamente.

\section{Delineamento metodológico da pesquisa}

O presente estudo é uma pesquisa-ação, de natureza exploratória e aplicada. Os dados foram gerados por meio de instrumentos, como: observação participante; registro fotográfico; e as produções textuais dos discentes em estudo. Os colaboradores da pesquisa foram a professora pesquisadora ${ }^{5}$ e os alunos do Curso Técnico em Eventos Integrado ao Ensino Médio do PROEJA IFPB/JP. A turma colaboradora era composta por 23 alunos, com idade entre 21 e 54 anos - sendo 6 homens e 17 mulheres - e muitos desempenhavam atividades profissionais em diversos setores do comércio 6 .

$\mathrm{Na}$ fase exploratória, aplicamos uma atividade de produção textual - autobiografia escolar - objetivando traçar o perfil dos alunos, sua história educacional até o momento que ingressaram no PROEJA e, sobretudo, acerca de suas expectativas e reais necessidades educacionais e cotidianas. Em seguida, analisamos o Livro Didático ${ }^{7}$ adotado pela Instituição participante, buscando identificar se as atividades de leitura e de produção textual estavam em consonância com os estudos norteadores do ensino da EJA, como também com as orientações oficiais que regulam o Ensino Médio, no qual o PROEJA está inserido.

Os resultados da fase exploratória da pesquisa sinalizaram que as especificidades dos cursos e dos discentes do PROEJA tornam inviável a utilização de recursos didáticos que foram desenvolvidos para o público do Ensino Médio da EJA em geral, uma vez que os cursos ofertados no Ensino Médio Profissionalizante do PROEJA requerem de seus discentes um aprendizado que viabilize conhecimentos específicos da área que estão se preparando para atuar profissionalmente. Ademais, inquietava-nos o fato de o livro didático ser de esfera nacional, ou seja, não considerar as especificidades regionais e locais de seus discentes, nem as propostas pedagógicas dos diferentes cursos do Ensino Médio Profissionalizante oferecidos nos diversos campi da Instituição participante.

Por sua vez, a autobiografia escolar revelou que a maior parte da turma colaboradora da pesquisa era composta por vendedores informais e/ou autônomos de produtos diversificados, como também por pessoas que já haviam desempenhado atividades de decoração e de produção de alimentos para eventos de pequeno porte. No tocante às expectativas sobre a parte prática do Curso que faziam, alguns desses discentes relataram que almejavam vivenciar a organização de um evento real em sua totalidade.

Sendo assim, desenvolvemos e aplicamos o projeto de letramento didático-temático intitulado "Empreender para vencer: ler, refletir e produzir textos do universo de Eventos", a

\footnotetext{
${ }^{5}$ A referida professora é uma das autoras deste artigo e, na ocasião do estudo, lecionava Língua Portuguesa no PROEJA na Instituição participante, o IFPB - Campus João Pessoa.

${ }^{6}$ A pesquisa foi submetida ao Comitê de Ética em Pesquisa da Universidade Estadual da Paraíba (UEPB) e aprovada pelo Parecer $\mathbf{n}^{\mathbf{0}} \mathbf{2 . 4 3 0 . 9 3 8}$, de 12 de dezembro de 2017.

${ }^{7}$ ALMEIDA, Neide Aparecida de et al. Coleção Viver, Aprender. Linguagem e Códigos Ensino Médio: linguagens e culturas - EJA. São Paulo: Global, 2013.
} 
fim de refletir acerca de uma proposta para o ensino de produção textual, com aplicabilidade na aula de Língua Portuguesa no Curso participante do estudo, respaldando-nos na utilização de gêneros textuais condizentes com a realidade social e profissional dos discentes em questão. No intuito de sistematizar as ações didáticas do projeto, elaboramos um Módulo do Aluno (vide Figura 1), dividido em três unidades temáticas: aprendendo a empreender; anunciar é preciso, lucrar é impreciso; divulgar para atrair: público em foco.

Os temas abordados nas unidades do módulo viabilizaram o entendimento dos passos necessários para a realização de uma feira de microempreendedorismo que a turma participante organizou na culminância do projeto. E as atividades propostas objetivaram, primordialmente, a aproximação dos alunos com a linguagem multimodal, partindo da prática de leitura e compreensão textual até a produção de textos multimodais.

Cabe explicar que a escolha dos gêneros a serem ensinados surgiu das demandas da prática social que os colaboradores da pesquisa intencionavam concretizar com o projeto. $\mathrm{Ou}$ seja, a entrevista, os anúncios publicitários, o convite e os panfletos produzidos pelos discentes ao longo das unidades do Módulo visaram à efetivação da Feira de Empreendedorismo, atividade motriz do projeto. Corroborando o pensamento de Kleiman (2006, p.33) de que é "a prática social que viabiliza a exploração do gênero, e não o contrário".

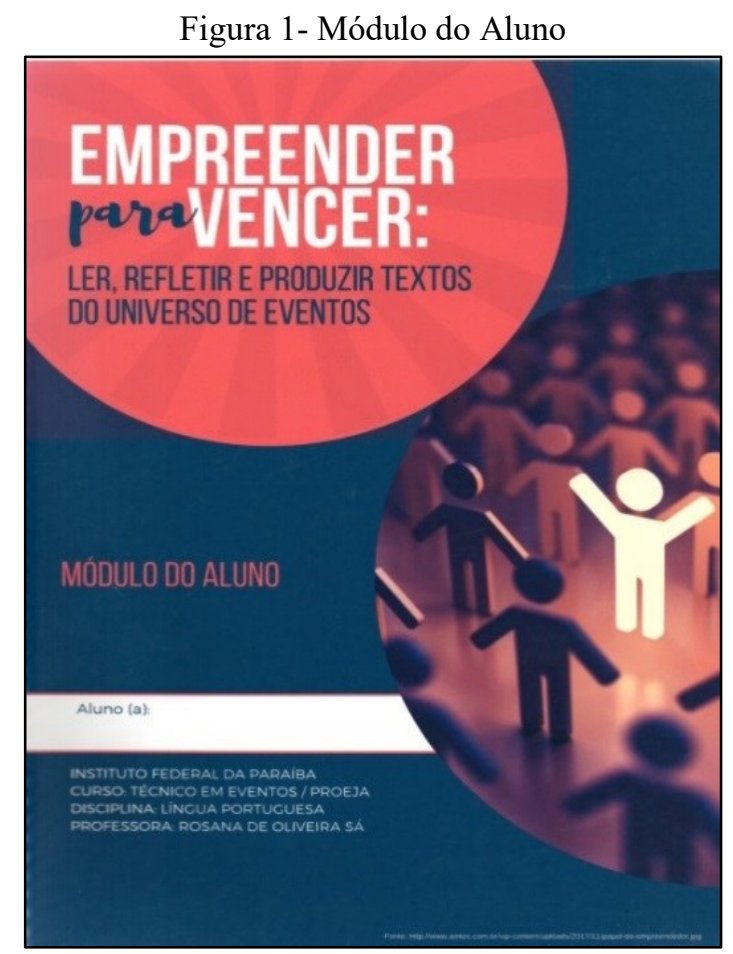

Fonte: Elaborado pela professora pesquisadora

Contudo, para que os que os discentes pudessem acompanhar o processo de intervenção e participar ativamente de cada etapa proposta, confeccionamos um módulo didático que fosse cumprido, em sua maioria, no ambiente da sala de aula, já que a maior parte dos alunos do PROEJA trabalha o dia todo e dispõe de pouco tempo em casa para realizar suas atividades escolares.

O tempo de execução do projeto foi de dois meses, totalizando 18 encontros, com duração de noventa minutos cada, e as ações didáticas corresponderam às unidades temáticas dispostas no Módulo do Aluno, divididas em três etapas, conforme detalhadas na seção seguinte. 
Volume 16 - Número 1 - jan/jul de 2021

\section{Relato da experiência e resultados}

Nesta seção, os resultados da fase aplicada da pesquisa serão apresentados em conformidade com as etapas de execução do projeto e de acordo com a ordem disposta no Módulo do Aluno:

- ETAPA 1: “Aprendendo a empreender". Nesta unidade, apresentamos o Módulo do Aluno e demos as orientações gerais do projeto, seguido da contextualização da proposta didática. Em seguida, introduzimos noções básicas de empreendedorismo, mostrando aos discentes a relevância desse conhecimento para atuar na área profissional de Eventos, uma vez que poderão constituir empresas organizadoras de cerimônias em geral. Foi aplicada uma sequência didática para aprofundamento do gênero entrevista, visando à preparação de uma conversa com uma professora $^{8}$ de Empreendedorismo e Marketing. Atividade interdisciplinar que culminou a etapa, conforme registrada na Figura 2 a seguir:

Figura 2: Registros do dia da entrevista

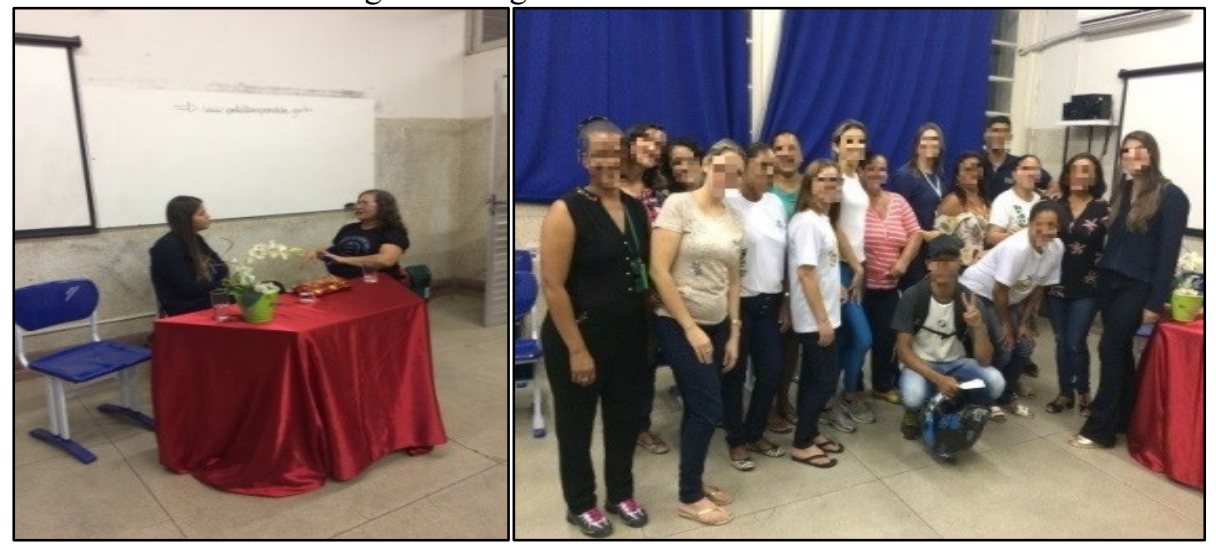

Fonte: Acervo da professora pesquisadora

- ETAPA 2: “Anunciar é preciso, lucrar é impreciso". Ênfase no gênero textual anúncio publicitário, refletindo acerca da utilização de recursos multissemióticos para atrair o públicoalvo da Feira, como também de diferentes formas de intertextualização. Abordamos alguns aspectos essenciais na produção de textos publicitários, como: público-alvo; propósito comunicativo; posicionamento dos recursos verbais e não verbais; o conceito/ideia que os anúncios procuram passar para o consumidor; as frases de efeito; os aspectos tipográficos; entre outros recursos para persuadir consumidores.

Nesta etapa, os discentes trabalharam em duplas, a fim de elaborar os anúncios publicitários dos produtos e serviços que foram comercializados na Feira de Empreendedorismo realizada no final do projeto didático. Segue uma breve amostragem da evolução dos colaboradores da pesquisa acerca do entendimento e da utilização de recursos multimodais para uma produção textual eficiente.

\footnotetext{
${ }^{8}$ Ao longo da fase aplicada do projeto, convidamos professores de diferentes disciplinas/áreas da Instituição participante, não apenas por serem conhecedores dos assuntos abordados no estudo, mas também para motivar projetos que propiciem práticas docentes interdisciplinares, com o objetivo de superar a fragmentação do conhecimento e "assumir uma visão de processo, defendendo a ideia do conhecimento como uma construção em rede, em diálogo entre as disciplinas” (BRASIL, 2007b, p.30).
} 
Volume 16 - Número 1 - jan/jul de 2021

Figura 3: Registros da evolução dos textos

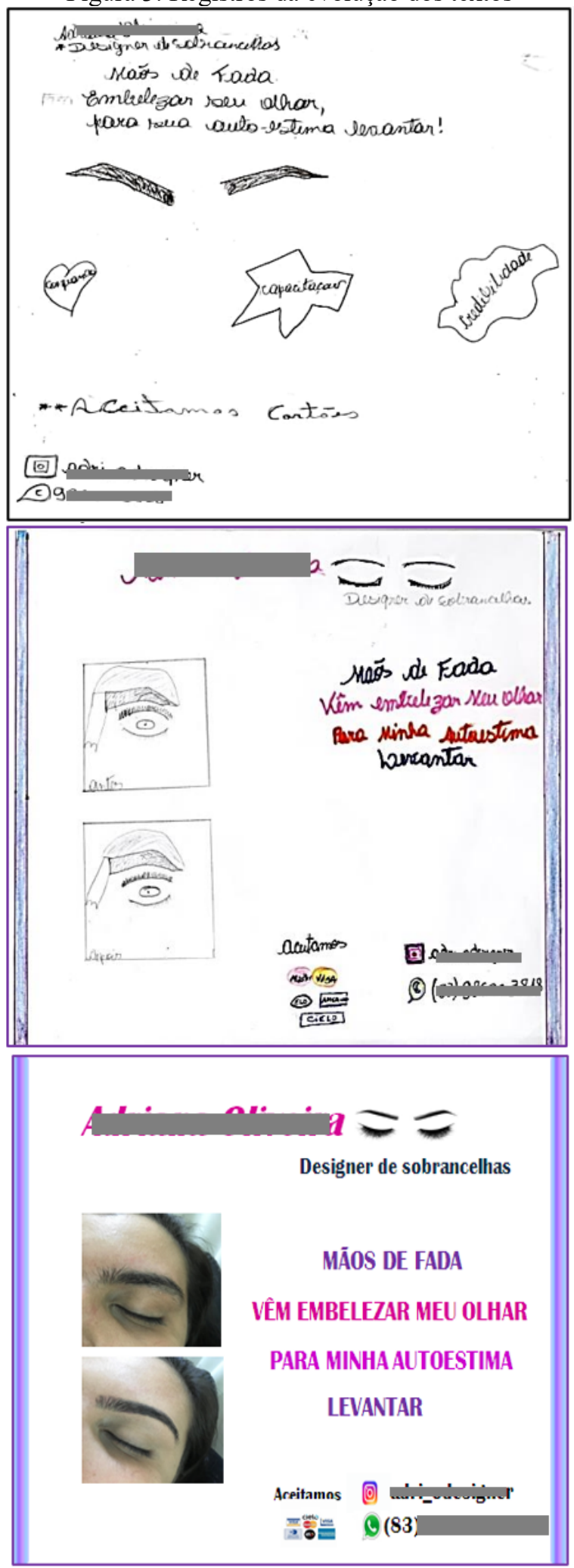

Fonte: Acervo da professora pesquisadora

- ETAPA 3: "Divulgar para atrair: público em foco". Nesta etapa, houve a colaboração de alguns docentes da Instituição participante, ajudando no planejamento das ações para a realização da "I Feira Empreender para Vencer - PROEJA/IFPB". O evento foi divulgado através da mescla dos gêneros convite e panfleto, produzidos pelos colaboradores da pesquisa 
em sala, com posterior divulgação nas salas de aula e murais da Instituição participante. Seguem registros desta etapa:

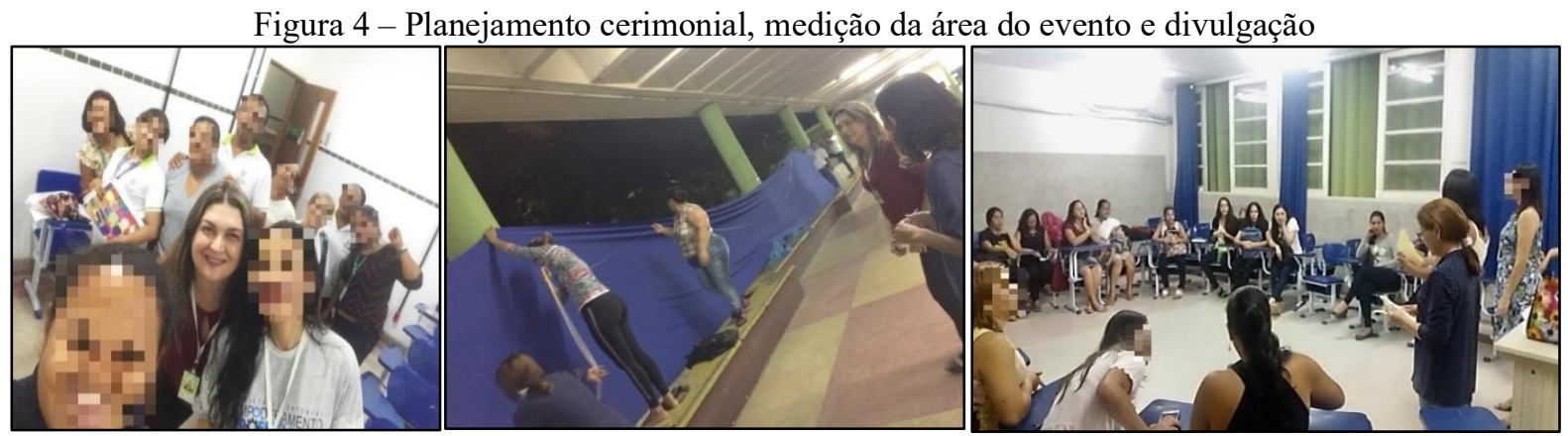

Fonte: Acervo da professora pesquisadora

Como mencionado, a realização da Feira marcou o encerramento do projeto. Para tanto, todas as ações foram planejadas e executadas pelos colaboradores da pesquisa sob a orientação da professora pesquisadora, contando também com a ajuda de professores visitantes, que efetivaram a parte interdisciplinar do projeto, colaborando em diferentes frentes: medição da área da Feira; organização do cerimonial; e participação nas atividades culturais que ocorreram no dia do evento.

A participação dos "alunos empreendedores" no momento da Feira superou as expectativas da professora pesquisadora, uma vez todos estavam engajados na missão de divulgar e vender seus produtos e serviços. Trabalharam em total cooperação com seus pares, inclusive, no momento do fechamento de caixa e da devolução dos estandes após o evento.

Vale registrar a alegria dos discentes no atendimento aos clientes no dia da Feira, como também a presença calorosa dos docentes e discentes das diversas modalidades da comunidade escolar participante.

Figura 5 - Solenidade de abertura, estandes, confraternização dos colaboradores

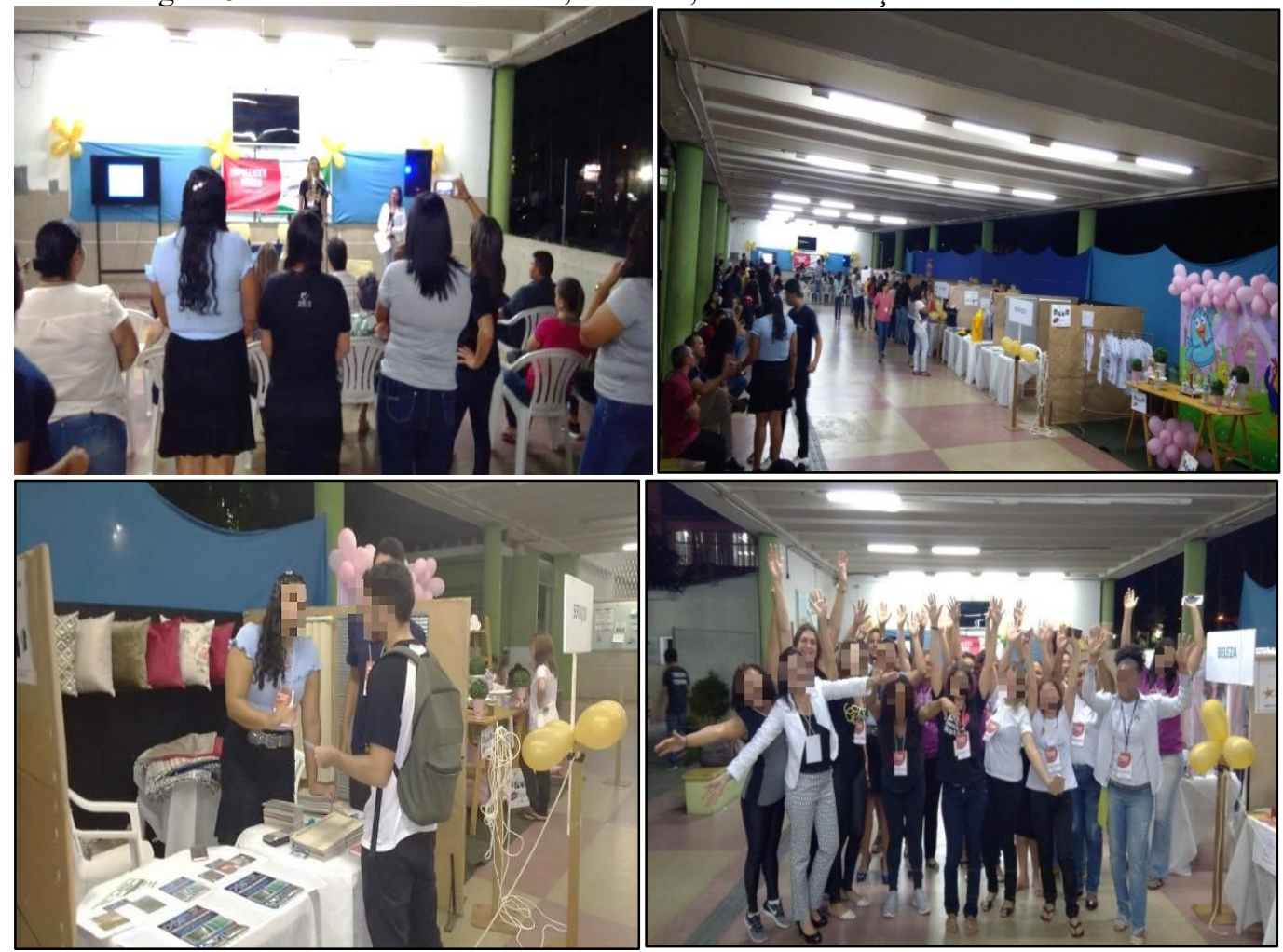

Fonte: Acervo da professora pesquisadora 
Os resultados obtidos ao longo da pesquisa revelam que não adianta o professor ser conhecedor de todas as teorias, se não as usa em prol dos alunos, se não as adapta para suprir as demandas da comunidade escolar na qual se dispõe a contribuir. Respeitar o perfil do educando parece ser o caminho para um processo de ensino e aprendizagem significativo. Fato comprovado na atividade final do projeto - Feira Empreender para Vencer - em que prevaleceu o exercício pleno da cidadania, revelado através da força do trabalho colaborativo, da união/interação conquistada mediante discussões sadias que objetivavam, unicamente, atingir um consenso que beneficiasse todos os atores envolvidos.

\section{Considerações finais}

Ao chegarmos à fase final desta pesquisa, percebemos que um dos caminhos que o professor de Língua Portuguesa pode trilhar para incentivar o processo de ensino e aprendizagem de produção textual na EJA Profissionalizante é trabalhar com projetos de letramento escolar que valorizem a leitura e a escrita para o exercício da cidadania. No entanto, com o desenrolar da pesquisa, aprendemos que isso não é o bastante para articularmos linguagem e cidadania no contexto escolar. Para iniciar esse tipo de prática pedagógica requer, primeiramente, um (re)posicionamento identitário do docente e das escolhas teóricometodológicas feitas por ele, a fim de promover uma melhor articulação entre teoria e prática.

Com base nessa nova percepção, trabalhamos, neste estudo, na perspectiva do letramento como fenômeno plural, crítico, capaz de desencadear ações que beneficiem a comunidade escolar participante além dos muros escolares. Situamos o texto como elemento central no processo de ensino e aprendizagem de língua materna (GERALDI, 2011), e evidenciamos o papel da linguagem como elemento facilitador de práticas sociais. Além disso, trabalhamos na perspectiva da multimodalidade como recurso metodológico nas aulas de produção textual, demonstrando a relevância da utilização de múltiplas linguagens para atingirmos nossos propósitos comunicativos.

No que concerne ao objetivo de desenvolver uma proposta metodológica para as aulas de Língua Portuguesa do PROEJA, constatamos que o projeto foi proveitoso, já que percebemos mudanças de atitude dos colaboradores da pesquisa nas aulas posteriores à intervenção, como: aumento de interesse em produção textual voltada para sua área de atuação profissionalizante; preocupação em atender ao público-alvo e ao propósito comunicativo dos textos que produziam; maior entendimento do que liam devido à atenção aos aspectos multimodais; e constante solicitação de ensino via projetos didáticos. Frutos que validam os saberes necessários à prática educativa transformadora, propostos por Freire (1996, p.21), em especial: "ensinar não é transferir conhecimento, mas criar as possibilidades para a sua própria produção ou a sua construção".

Diante dos desdobramentos positivos mencionados, compreendemos que as contribuições deste estudo podem ir além do contexto pesquisado, uma vez que refletir acerca de ações didáticas promovidas por nós ou por outrem facilita a compreensão dos desafios de um cotidiano docente e discente possivelmente comum a outras instituições que lidam com a Educação Profissionalizante de Jovens e Adultos.

\section{Referências}

ANTUNES, Irandé. Aula de português: encontro \& interação. São Paulo: Parábola, 2003. BRASIL. Ministério da Educação. Secretaria da Educação Média e Tecnológica. Parâmetros Curriculares Nacionais Ensino Médio. Brasília: MEC, 2000. 
Volume 16 - Número 1 - jan/jul de 2021

BRASIL. Ministério da Educação. Secretaria de Ensino Médio e Tecnológico. PCN+ Ensino Médio - Orientações Educacionais Complementares aos Parâmetros Curriculares Nacionais: linguagens, códigos e suas tecnologias. Brasília: MEC, 2002.

BRASIL. Ministério da Educação. Secretaria de Educação Básica. Conhecimentos de língua portuguesa. Orientações Curriculares para o Ensino Médio: linguagens, códigos e suas tecnologias. Brasília: MEC, 2006.

BRASIL. Ministério da Educação. Educação Profissional Técnica de Nível Médio Integrada ao Ensino Médio. Documento Base. Brasília, DF: MEC, 2007a.

BRASIL. Ministério da Educação. PROEJA: Programa Nacional de Integração da Educação Profissional com a Educação Básica na Modalidade de Educação de Jovens e Adultos: Documento Base - Formação inicial e continuada / Ensino Fundamental. Brasília, DF: MEC, 2007b.

BRASIL. Ministério da Educação. Secretaria de Educação Básica. Diretoria de Currículos e Educação Integral. Diretrizes Curriculares Nacionais da Educação Básica. Brasília: MEC, SEB, DICEI, 2013.

BRASIL. Ministério da Educação. Secretaria de Educação Básica. 2018. Base Nacional Comum Curricular: educação é a base. Disponível em: $<$ http://basenacionalcomum.mec.gov.br/a-base $>$. Acesso em: 21 jan.2020.

BRONCKART. Atividade de linguagem, discurso e desenvolvimento humano. Campinas, SP: Mercado de Letras, 2006.

DIONÍSIO, Angela Paiva; VASCONCELOS, Leila Janot de. Multimodalidade, gênero textual e leitura. In: BUNZEN, Clecio; MENDONÇA, Márcia (Orgs.). Múltiplas linguagens para o ensino médio. São Paulo: Parábola, 2013, p. 19-42.

FREIRE, Paulo. Pedagogia da autonomia: saberes necessários à prática educativa. São Paulo: Paz e Terra, 1996.

GERALDI, J. W. (Org.). O texto na sala de aula. 5. ed. São Paulo: Ática, 2011.

KLEIMAN, Angela B. Leitura e prática social no desenvolvimento de competências no ensino médio. In: BUNZEN, Clécio; MENDONÇA, Márcia (Orgs). Português no Ensino Médio e formação de professor. São Paulo: Parábola, 2006, p.23-36.

MARCUSCHI, L. A. Produção textual, análise de gêneros e compreensão. São Paulo: Parábola Editorial, 2008.

MAYER, Richard E. Introduction to Multimedia Learning. In:

2nd ed. Cambridge: Cambridge University Press, 2009, p.01-57.

Multimedia Learning.

OLIVEIRA, Maria do S.; TINOCO, Glícia A.; SANTOS, Ivoneide B. de A. Projetos de letramento e formAÇÃo de professores de língua materna. Natal: EDUFRN, 2014. RIBEIRO, Ana Elisa. Textos multimodais: leitura e produção. São Paulo: Parábola, 2016. ROJO, R. Letramentos múltiplos, escola e inclusão social. São Paulo: Parábola, 2009.

SUASSUNA, Lívia; MELO, Iran F. de; COELHO, Wanderley Elias. O projeto didático: forma de articulação entre leitura, literatura, produção de texto e análise linguística. In: BUNZEN, Clécio; MENDONÇA, Márcia (Orgs.). Português no Ensino Médio e formação de professor. São Paulo: Parábola, 2006, p. 227-244. 